\title{
Detection of Asthmatic Cough on Basis of Bronchodilator Responsiveness by the Forced Oscillation Technique and 3-Dimentional Imaging: A Case Report
}

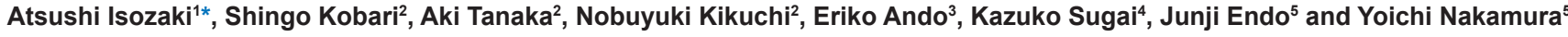 \\ ${ }^{1}$ Division of Pediatrics, Medical Center for Allergy and Immune Diseases, Yokohama City Minato Red Cross Hospital, Japan \\ ${ }^{2}$ Department of Pediatrics, Yokohama City Minato Red Cross Hospital, Japan \\ ${ }^{3}$ Department of Pediatrics, Kawasaki City Kawasaki Hospital, Japan \\ ${ }^{4}$ Department of Pediatrics, National Hospital Organization Yokohama Medical Center, Japan \\ ${ }^{5}$ Department of Allergology, Medical Center for Allergy and Immune Diseases, Yokohama City Minato Red Cross Hospital, Japan
}

\begin{abstract}
When asthmatic patients present with cough, especially cough without wheezing, it is difficult to determine if the cough was due to asthma. A 7-year-old girl presented with persistent cough without wheezing and exacerbation of asthma. We performed bronchodilator reversibility test by determining the respiratory resistance. Respiratory resistance and impedance were measured by using the Forced Oscillation Technique (FOT) with MostGraph-01 (Chest CO., LTD., Japan). The changes were observed in colored 3-dimensional imaging patterns. The images clearly showed that the patient's respiratory resistance decreased after administration of the bronchodilator. The measurement of respiratory impedance by the forced oscillation technique attributes to diagnose asthma.
\end{abstract}

Keywords: Asthma; Childhood; Forced oscillation technique; Respiratory function; Respiratory reversi

\section{Introduction}

When asthmatic patients present with cough, especially cough without wheezing, it is sometimes difficult for physicians to determine whether the cough is caused by asthma. Our patient was a 7-year-old girl who had persistent cough with exacerbated asthma and no wheezing. We performed a bronchodilator reversibility test to determine respiratory resistance. Respiratory resistance and impedance were measured by the Forced Oscillation Technique (FOT) using MostGraph-01 (Chest CO., LTD., Japan) [1]. The results of MostGraph-01 were obtained as 3 -dimensional images. The images clearly showed that her respiratory resistance decreased after administration of the bronchodilator.

\section{Case Report}

A 7-year-old girl visited the pediatric department in our hospital because of persistent cough from the previous night. She had asthma since the age of 3 years and was on controller medication, including inhaled corticosteroids (ciclesonide, $200 \mu \mathrm{g}$ per day) and a leukotriene receptor antagonist (montelukast, $5 \mathrm{mg}$ per day); there was no chest tightness and wheezing. At the time of arrival at the hospital, her consciousness was clear. Her body temperature was $36.4^{\circ} \mathrm{C}$, and the respiratory rate was 21 cycles per minute. Her body weight was 24.0 $\mathrm{kg}$ and height was $105.3 \mathrm{~cm}$. The patient's oxygen saturation level was $100 \%$. The concentration of exhaled Nitric Oxide (NIOX MINO, Karolinska Institute, Sweden) was $18 \mathrm{ppb}$. Her respiratory sound was clear without any wheezing even on forced breathing.

Therefore, we performed a bronchodilator reversibility test by determining respiratory function, respiratory resistance, and impedance. Salbutamol $(0.2 \mathrm{~mL}$ of $200 \mathrm{mg})$ and normal saline $(2 \mathrm{~mL})$ were administered through a nebulizer (NE-C28-E; Omron Healthcare, CO. LTD., Tokyo, Japan) to assess bronchodilator responsiveness. Spirometric and respiratory resistance and impedance measurements were repeated $15 \mathrm{~min}$ after bronchodilator administration. Respiratory resistance (Rrs) and reactance (Xrs) were measured before spirometry to account for the influence of forced exhalation maneuvers on airway function [2].
Respiratory function was measured according to the ATS criteria [3]. Forced vital capacity (FVC), forced expiratory volume in $1 \mathrm{~s}\left(\mathrm{FEV}_{1 \%}\right.$ ', ratio of FEV1 to FVC ( $\mathrm{FEV}_{1 \%}$, Peak Expiratory Flow (PEF), forced expiratory flow at $50 \%$ vital capacity (V50), and $\mathrm{PEF}_{25-75}$ were measured by computerized spirometry (CHESTAC-8800; Chest M.I., CO. LTD. Tokyo, Japan). Respiratory resistance and impedance were measured by FOT using MostGraph-01 (Chest CO., LTD., Japan). Both random noise and Hunning impulse were recorded as oscillation signals. Impulse-oscillation signals generated by a loud speaker were applied at intervals of $0.25 \mathrm{~s}$ through the mouthpiece during tidal breathing at rest. We measured the mouth pressure and flow signals and obtained the Rrs and Xrs against oscillatory frequencies ranging from 5 to $35 \mathrm{~Hz}$. During measurements, the patient sat with her neck in a comfortable neutral posture and supported her cheeks firmly to reduce upper airway shunting. The curves of Rrs and Xrs versus frequency could be obtained for every $0.25 \mathrm{~s}$, and the values were serially plotted against time with assigned color gradients; this procedure provided colored 3-dimensional imaging patterns. The results of oscillation or expiration tests were obtained as mean values of inspiration and expiration phases, or mean changes during a respiratory cycle, thus enabling wholebreath or within-breath (inspiratory-expiratory) analyses. We selected the reliable result from three times measurements of MostGrapf-01 because the upper airway shunt effect and the interference due to spontaneous ventilation are important source of errors in impedance measurements.

${ }^{*}$ Corresponding author: Atsushi Isozaki, MD, Department of Pediatrics, Medical Center for Allergy and Immune Diseases, Yokohama City Minato Red Cross Hospital 3-12-1 Shin-yamashita, Naka-ku, Yokohama City, Japan, Tel: 81-45 6100; Fax: 81-45-6101; E-mail: isozaki.ped@yokohama.jrc.or.jp

Received June 20, 2012; Accepted September 11, 2012; Published Septembe 13, 2012

Citation: Isozaki A, Kobari S, Tanaka A, Kikuchi N, Ando E, et al. (2012) Detection of Asthmatic Cough on Basis of Bronchodilator Responsiveness by the Forced Oscillation Technique and 3-Dimentional Imaging: A Case Report. J Clin Case Rep 2:178. doi:10.4172/2165-7920.1000178

Copyright: @ 2012 Isozaki A, et al. This is an open-access article distributed under the terms of the Creative Commons Attribution License, which permits unrestricted use, distribution, and reproduction in any medium, provided the original author and source are credited. 
In this case, we used Rrs at 5 and $20 \mathrm{~Hz}$ (R5 and R20, respectively), and the difference between R5 and R20 (R5-R20) was an indicator of the frequency dependence of Rrs [3], which is supported to reflect the inhomogeneous ventilator mechanics [4]. We also used Xre at $5 \mathrm{~Hz}$ (X5), which reflects the elastic or inertial properties of the lung, and the resonant frequency (Fres) at which Xres crosses zero and the elastic forces are equal in magnitude and opposite, so as area of low Xrs (ALX) reflects the elastic forces.

The changes in spirometry values with bronchodilator responsiveness are shown in table 1. Bronchodilator administration improved $\mathrm{FEV}_{1}$ by $12.0 \%$, V50 by $28.8 \%$ and $\mathrm{FEF}_{25-75}$ by $46.7 \%$. Moreover, Rrs also decreased after administration of the bronchodilator; R5, in particular, decreased by $38.9 \%$. R5-R20 decreased by $70.8 \%$. In terms of respiratory impedance, X5, Fres, and ALX improved (Table 2). The changes observed in colored 3-dimensional imaging patterns are shown in figure
1. The images clearly showed that the patient's respiratory resistance decreased after administration of the bronchodilator.

We diagnosed that her cough was caused by exacerbation of asthma. Her cough disappeared after administration of a long-acting beta-agonist (salmeterol, $25 \mu \mathrm{g} \times 2 /$ day) for 3 days by regular inhalation along with the controller medications.

\section{Discussion}

When asthmatic patients present with cough, especially cough without any wheezing, it is difficult for physicians to determine whether the cough is caused by asthma. Cough can be caused by common cold and not just by exacerbation of asthma. An objective examination is required to diagnose the underlying condition in such patients. We diagnosed that the present cough was caused by exacerbation of asthma, because $\mathrm{FEV}_{1}$ was improved more than $12 \%$ along with improvement of respiratory resistance and impedance in 3-dementional graphics.

\begin{tabular}{|l|l|l|l|l|l|}
\hline & & Pre-bronchodilator & (\% predict value) & Post- bronchodilator & Ratio of change (\%) \\
\hline FVC & (L) & 1.51 & $(98.1)$ & 1.54 & $+4.5 \%$ \\
\hline FEV ${ }_{1}$ & (L) & 1.36 & $(100.7)$ & 1.48 & $+12.0 \%$ \\
\hline FEV $_{1 \%}$ & $(\%)$ & 90.1 & & 96.1 & $+6.0 \%$ \\
\hline PEF & $(\mathrm{L} / \mathrm{s})$ & 3.50 & $(145.8)$ & 3.04 & $-13.1 \%$ \\
\hline V50 & $(\mathrm{L} / \mathrm{s})$ & 1.77 & $(94.1)$ & 2.28 & $+28.8 \%$ \\
\hline FEF $_{25-75}$ & $(\mathrm{~L} / \mathrm{s})$ & 1.50 & $(82.9)$ & 2.20 & $+46.7 \%$ \\
\hline
\end{tabular}

Table 1: Changes in Respiratory Function, with Bronchodilator Responsiveness.

\begin{tabular}{|l|l|l|l|l|}
\hline & & Pre- bronchodilator & Post- bronchodilator \\
\hline R5 & $\left(\mathrm{cmH}_{2} \mathrm{O} / \mathrm{L} / \mathrm{s}\right)$ & 8.88 & 5.35 & Ratio of change (\%) \\
\hline R20 & $\left(\mathrm{cmH}_{2} \mathrm{O} / \mathrm{L} / \mathrm{s}\right)$ & 6.62 & 4.69 & $-39.8 \%$ \\
\hline R5-R20 & $\left(\mathrm{cmH}_{2} \mathrm{O} / \mathrm{L} / \mathrm{s}\right)$ & 2.26 & 0.66 & $-29.2 \%$ \\
\hline X5 & $\left(\mathrm{cmH}_{2} \mathrm{O} / \mathrm{L} / \mathrm{s}\right)$ & -1.21 & -0.77 & $-70.8 \%$ \\
\hline Freq & $(\mathrm{Hz})$ & 9.94 & $+36.4 \%$ & $-21.7 \%$ \\
\hline ALX & $\left(\mathrm{cmH}_{2} \mathrm{O} / \mathrm{L} / \mathrm{s} . \mathrm{Hz}\right)$ & 4.99 & $-44.1 \%$ \\
\hline
\end{tabular}

Table 2: Changes in Respiratory Resistance and Impedance, with Bronchodilator Responsiveness.

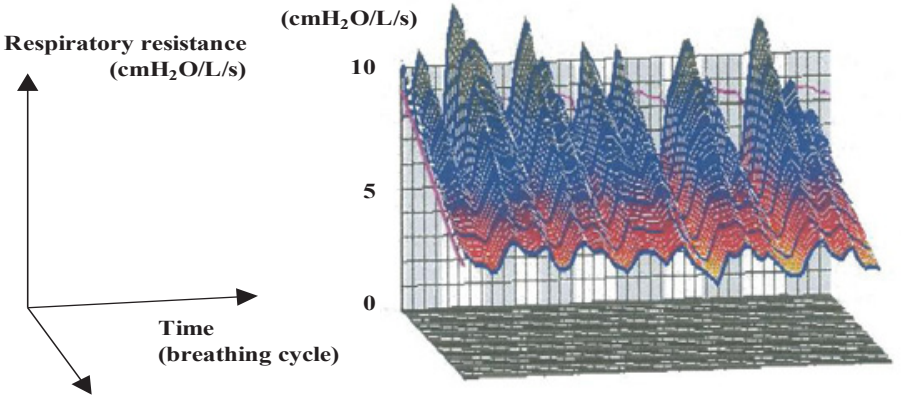

Oscillatory frequency
Pre-bronchodilator

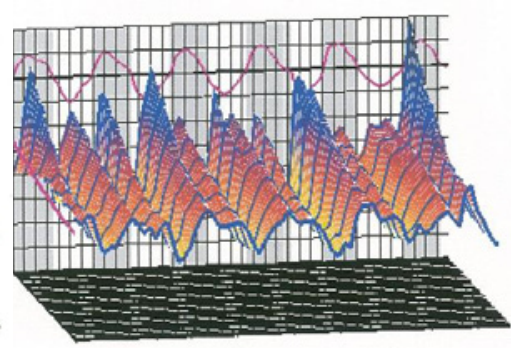

Post-bronchodilator

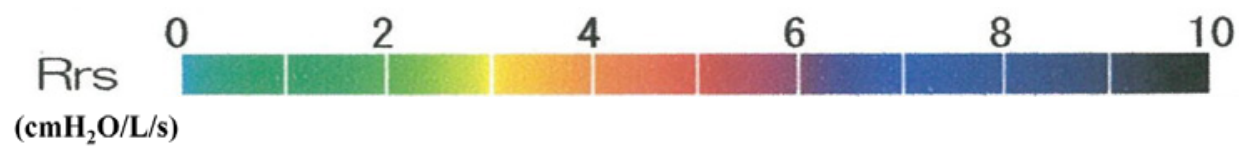

Figure 1: Three-dimensional images of respiratory resistance, with bronchodilator responsiveness, showing a clear decrease after bronchodilator administration. The images clearly showed that the patient's respiratory resistance decreased after administration of the bronchodilator. 
The forced oscillation technique is currently used for the measurement of respiratory resistance, and MasterScreen-IOS (CareFusion CO., LTD., Hoechberg, Germany) is used worldwide. MostGraph-01 has been recently developed by Krosawa in Japan [1]. Some reports describe the correlations between MasterScreen-IOS and respiratory function $[5,6]$. The age and height of subjects influence these measurements most strongly; however, respiratory resistance and reactance depends on the frequency of the oscillation in healthy, young children.

In contrast to spirometry, the measurement of respiratory resistance and reactance does not require forced breathing; thus, it can be performed in younger children. In addition, MostGraph-01 measurements can be performed in 10 to $15 \mathrm{~s}$, and the technique is easy and convenient. Finally, the results obtained are easy to understand, since the data measured by MostGraph-01 is presented in the form of colored, 3-dimensional graphics, with respiratory resistance and reactance being measured in real-time during the expiration and inspiration phases. Veiga et al. described that respiratory impedance of asthmatic patients is higher than that of healthy controls in total respiratory cycle by using mono frequency FOT [7]. R5, R20 and R5R20 decreased at expiratory and inspiratory phase after bronchodilator administration in the present patients.

The measurement of respiratory impedance by the forced oscillation technique with MasterScreen-IOS for childhood asthma has helped in evaluating asthma status, such as assessments of bronchodilator response [8-10], bronchial hyper responsiveness, and exercise-induced airway obstruction [11-13]. It has been reported that about 30\% decreases in R5 is evaluated by bronchodilator response in asthmatic children [8-10]. In the near future, similar assessments using MostGraph-01 will be possible and will help clinicians in controlling childhood asthma. Cavalcanti et al. described the FOT can be proposed as an alternative method for the assessment of the respiratory mechanics in asthmatic patients [14].

Taken together, the results suggest that MostGraph-01 is a useful examination tool for the diagnosis and management of childhood asthma. The measurement of respiratory impedance by the forced oscillation technique attributes to diagnose asthma. LaPrad and Lutchen described that new and deeper insights on how the human asthmatic whole lung emerges are likely [15]. However, it is necessary to establish how best to employ each of its parameters and to produce reference values for bronchodilator responses in children before clinical use.

\section{References}

1. Kurosawa H (2010) MostGraph no kaihatu to oyo. Kokyu 29: 40-47.

2. Mori K, Shirai T, Mikamo M, Shishido Y, Akita T, et al. (2011) Colored 3-dimensional analyses of respiratory resistance and reactance in COPD and asthma. COPD 8: 456-463.

3. (1991) Lung function testing: selection of reference values and interpretative strategies. American Thoracic Society. Am Rev Respir Dis 144: 1202-1218.

4. Dellacà RL, Pompilio PP, Walker PP, Duffy N, Pedotti A, et al. (2009) Effect of bronchodilation on expiratory flow limitation and resting lung mechanics in COPD. Eur Respir J 33: 1329-1337.

5. Olaguíbel JM, Alvarez-Puebla MJ, Anda M, Gómez B, García BE, et al. (2005) Comparative analysis of the bronchodilator response measured by impulse oscillometry (IOS), spirometry and body plethysmography in asthmatic children. $\mathrm{J}$ Investig Allergol Clin Immunol 15: 102-106.
6. Song TW, Kim KW, Kim ES, Kim KE, Sohn MH (2008) Correlation between spirometry and impulse oscillometry in children with asthma. Acta Paediatr 97: 51-54.

7. Veiga J, Lopes AJ, Jansen JM, Melo PL (2009) Within-breath analysis of respiratory mechanics in asthmatic patients by forced oscillation. Clinics (Sao Paulo) 64: 649-656.

8. Bailly C, Crenesse D, Albertini M (2011) Evaluation of impulse oscillometry during bronchial challenge testing in children. Pediatr Pulmonol 46: 1209-1214.

9. Nair A, Ward J, Lipworth BJ (2011) Comparison of bronchodilator response in patients with asthma and healthy subjects using spirometry and oscillometry. Ann Allergy Asthma Immunol 107: 317-322.

10. Bailly C, Crenesse D, Albertini M (2011) Evaluation of impulse oscillometry during bronchial challenge testing in children. Pediatr Pulmonol 46: 1209-1214.

11. Horsman TA, Duke RK, Davenport PW (2009) Airway response to mannito challenge in asthmatic children using impulse oscillometry. J Asthma 46: 600603.

12. Jee HM, Kwak JH, Jung da W, Han MY (2010) Useful parameters of bronchial hyperresponsiveness measured with an impulse oscillation technique in preschool children. J Asthma 47: 227-232.

13. Aronsson D, Tufvesson E, Bjermer L (2011) Comparison of central and peripheral airway involvement before and during methacholine, mannitol and eucapnic hyperventilation challenges in mild asthmatics. Clin Respir J 5: 10-18.

14. Cavalcanti JV, Lopes AJ, Jansen JM, Melo PL (2006) Detection of changes in respiratory mechanics due to increasing degrees of airway obstruction in asthma by the forced oscillation technique. Respir Med 100: 2207-2219.

15. LaPrad AS, Lutchen KR (2008) Respiratory impedance measurements for assessment of lung mechanics: focus on asthma. Respir Physiol Neurobio 163: 64-73. 